\title{
SABERES DOCENTES E FORMAÇÃO DE PROFESSORES: UM BREVE PANORAMA DA PESQUISA BRASILEIRA
}

\author{
Célia Maria Fernandes Nunes *
}

\begin{abstract}
RESUMO: As pesquisas sobre formação e profissão docentes apontam para uma revisão da compreensão da prática pedagógica do professor, que é tomado como mobilizador de saberes profissionais. Considera-se assim que este, em sua trajetória, constrói e reconstrói seus conhecimentos conforme a necessidade de sua utilização, suas experiências, seus percursos formativos e profissionais etc. $\mathrm{O}$ objetivo deste texto é apresentar uma análise de como e quando a questão dos saberes docentes aparece nas pesquisas sobre formação de professores na literatura educacional brasileira, identificando as diferentes referências e abordagens teórico-metodológicas que os fundamentam, os enfoques e tipologias utilizadas e criadas por pesquisadores brasileiros. Acredita-se que a investigação dessa temática possibilitará identificar um percurso de pesquisa desenvolvido com características próprias, mas em compasso com uma tendência internacional no âmbito das pesquisas sobre o ensino e sobre os docentes.
\end{abstract}

Palavras-chave: saberes docentes, conhecimento, formação de professores, pesquisa educacional, ensino.

As pesquisas sobre formação e profissão docente apontam para uma revisão da compreensão da prática pedagógica do professor, que é tomado como mobilizador de saberes profissionais. Considera-se, assim, que este, em sua trajetória, constrói e reconstrói seus conhecimentos conforme a necessidade de utilização dos mesmos, suas experiências, seus percursos formativos e profissionais.

A discussão sobre o tema surge em âmbito internacional nas décadas de 1980 e 1990. Entre alguns dos motivos que contribuíram para a sua emergência está o movimento de profissionalização do ensino e

\footnotetext{
* Professora assistente da Universidade Federal de Ouro Preto (UFOP), doutoranda em Educação na Pontifícia Universidade Católica do Rio de Janeiro (PUC-Rio). E-mail: cadu@feop.com.br
} 
suas conseqüências para a questão do conhecimento dos professores na busca de um repertório de conhecimentos, visando a garantir a legitimidade da profissão, havendo a partir daí uma ampliação tanto quantitativa, quanto, posteriormente, qualitativa desse campo (Tardif, 2000). No contexto das pesquisas educacionais brasileiras, ${ }^{1}$ a temática dos saberes docentes tem se mostrado uma área um tanto recente, o que vem demandando estudos sob diferentes enfoques.

O objetivo do presente trabalho é apresentar uma análise de como e quando a questão dos saberes docentes aparece nas pesquisas sobre formação de professores na literatura educacional brasileira; num segundo momento, identificar as diferentes referências e abordagens teórico-metodológicas que os fundamentam, os enfoques e tipologias utilizadas e criadas por pesquisadores brasileiros.

\section{Surgimento e características do debate no âmbito nacional}

As pesquisas sobre formação de professores têm destacado a importância de se analisar a questão da prática pedagógica como algo relevante, opondo-se assim às abordagens ${ }^{2}$ que procuravam separar formação e prática cotidiana. Na realidade brasileira, embora ainda de uma forma um tanto "tímida", é a partir da década de 1990 que se buscam novos enfoques e paradigmas para compreender a prática pedagógica e os saberes pedagógicos e epistemológicos relativos ao conteúdo escolar a ser ensinado/aprendido. Neste período, inicia-se o desenvolvimento de pesquisas que, considerando a complexidade da prática pedagógica e dos saberes docentes, buscam resgatar o papel do professor, destacando a importância de se pensar a formação numa abordagem que vá além da acadêmica, envolvendo o desenvolvimento pessoal, profissional e organizacional da profissão docente.

Neste contexto, as pesquisas sobre a formação de professores e os saberes docentes surgem com marca da produção intelectual internacional, ${ }^{3}$ com o desenvolvimento de estudos que utilizam uma abordagem téorico-metodológica que dá a voz ao professor, a partir da análise de trajetórias, histórias de vida etc. Segundo Nóvoa (1995), esta nova abordagem veio em oposição aos estudos anteriores que acabavam por reduzir a profissão docente a um conjunto de competências e técnicas, gerando uma crise de identidade dos professores em decorrência de uma separação entre o eu profissional e o eu pessoal. Essa virada nas investigações passou a ter o professor como foco central em 
estudos e debates, considerando o quanto o "modo de vida" pessoal acaba por interferir no profissional. Acrescenta ainda o autor que esse movimento surgiu "num universo pedagógico, num amálgama de vontades de produzir um outro tipo de conhecimento, mais próximo das realidades educativas e do quotidiano dos professores" (p. 19).

Passou-se a estudar a constituição do trabalho docente levando-se em conta os diferentes aspectos de sua história: individual, profissional etc. Percebe-se, então, uma "virada" nos estudos, que passam a reconhecer e considerar os saberes construídos pelos professores, o que anteriormente não era levado em consideração. Nessa perspectiva de analisar a formação de professores, a partir da valorização destes, é que os estudos sobre os saberes docentes ganham impulso e começam a aparecer na literatura, numa busca de se identificarem os diferentes saberes implícitos na prática docente. Nesse espírito, tinha-se em vista que "é preciso investir positivamente os saberes de que o professor é portador, trabalhando-os de um ponto de vista teórico e conceptual" (Nóvoa, 1992, p. 27).

O texto apresentado por Fiorentini et al. (1998) nos mostra a tendência crescente das pesquisas, em nossa realidade, de procurar valorizar o estudo dos saberes docentes na formação de professores. Segundo o autor, de uma valorização quase exclusiva do conhecimento (isto é, dos saberes específicos) que o professor tinha sobre a sua disciplina, característica da década de 1960, passa-se, na década de 1970, à valorização dos aspectos didáticos-metodológicos relacionados às tecnologias de ensino, passando para um segundo plano o domínio dos conteúdos. Nos anos de 1980, o discurso educacional é dominado pela dimensão sóciopolítica e ideológica da prática pedagógica. A idealização de um modelo teórico para orientar a formação do professor conduzia a uma análise negativa da prática pedagógica e dos saberes docentes.

as pesquisas sobre ensino e formação de professores passaram a priorizar o estudo de aspectos políticos e pedagógicos amplos. Os saberes escolares, os saberes docentes tácitos e implícitos e as crenças epistemológicas, como destaca Linhares (1996), seriam muito pouco valorizados e raramente problematizados ou investigados tanto pela pesquisa acadêmica educacional como pelos programas de formação de professores. Embora, neste período, as práticas pedagógicas de sala de aula e os saberes docentes tenham começado a ser investigados, as pesquisas não tinham o intuito de explicitá- los e/ou valorizá-los como formas válidas ou legítimas de saber. (p. 314) 
Já os anos 1990 foram marcados pela busca de novos enfoques e paradigmas para a compreensão da prática docente e dos saberes dos professores, embora tais temáticas ainda sejam pouco valorizadas nas investigações e programas de formação de professores.

Repensando a formação dos professores a partir da análise da prática pedagógica, Pimenta (1999) identifica o aparecimento da questão dos saberes como um dos aspectos considerados nos estudos sobre a identidade da profissão do professor. Parte da premissa de que essa identidade é construída a partir da

significação social da profissão; da revisão constante dos significados sociais da profissão; da revisão das tradições. Mas também da reafirmação das práticas consagradas culturalmente e que permanecem significativas. Práticas que resistem a inovações porque prenhes de saberes válidos às necessidades da realidade. Do confronto entre as teorias e as práticas, da análise sistemática das práticas à luz das teorias existentes, da construção de novas teorias. (p. 19)

Dessa forma, resgata a importância de se considerar o professor em sua própria formação, num processo de auto-formação, de reelaboração dos saberes iniciais em confronto com sua prática vivenciada. Assim seus saberes vão-se constituindo a partir de uma reflexão na e sobre a prática. Essa tendência reflexiva vem-se apresentando como um novo paradigma na formação de professores, sedimentando uma política de desenvolvimento pessoal e profissional dos professores e das instituições escolares.

Segundo o que Silva (1997) identifica em sua pesquisa, os estudos educacionais trouxeram, a partir do final dos anos de 1980, novos conceitos $^{4}$ para a compreensão do trabalho docente. Destaca que as novas abordagens de pesquisa passaram a reconhecer o professor como sujeito de um saber e de um fazer, fazendo surgir a necessidade de se investigarem os saberes de referência dos professores sobre suas próprias ações e pensamentos, já que

a análise dos valores e princípios de ação que norteiam o trabalho dos professores pode trazer novas luzes sobre nossa compreensão acerca dos fundamentos do trabalho docente, seja no sentido de desvendar atitudes e práticas presentes no dia-a-dia das escolas que historicamente foram ignoradas pela literatura educacional (e talvez possam trazer contribuições para o trabalho e a formação de professores)". (p. 3) 
Em seu estudo, a autora afirma que todos os professores entrevistados revelam a existência de um conhecimento profissional que vai sendo construído ao longo da carreira, apesar das características e trajetórias distintas, o qual precisa ser conhecido, já que o mesmo norteia a prática educativa. Segundo ela, "de qualquer modo, quer para afirmá-los (e valorizá-los) quer para negá-los (e confrontá-los com visões alternativas de escola e mundo) há que se conhecer este saber docente que rotineiramente norteia as práticas educativas" (p. 14). Ressalta, no entanto, que o fato de pensar/produzir uma teoria a partir da prática educativa, considerando a sabedoria e experiência dos professores, não significa a negação do papel da teoria na produção do conhecimento.

Therrien (1995) salienta o quanto os estudos sobre a formação do professor ainda persistem numa dissociação entre a formação e a prática cotidiana, não enfatizando a questão dos saberes que são mobilizados na prática, ou seja, os saberes da experiência. ${ }^{5}$ Esse saberes são transformados e passam a integrar a identidade do professor, constituindo-se em elemento fundamental nas práticas e decisões pedagógicas, sendo, assim, caracterizados como um saber original. Essa pluralidade de saberes que envolve os saberes da experiência é tida como central na competência profissional e é oriunda do cotidiano e do meio vivenciado pelo professor. Segundo o autor,

esses saberes da experiência que se caracterizam por serem originados na prática cotidiana da profissão, sendo validados pela mesma, podem refletir tanto a dimensão da razão instrumental que implica num saber-fazer ou saber-agir tais como habilidades e técnicas que orientam a postura do sujeito, como a dimensão da razão interativa que permite supor, julgar, decidir, modificar e adaptar de acordo com os condicionamentos de situações complexas. (p. 3)

Estudos como estes têm destacado a importância do desenvolvimento de pesquisas, em nossa realidade, que busquem identificar e analisar os saberes docentes numa perspectiva de contribuir para a ampliação do campo e para a implementação de políticas que envolvam a questão da formação do professor, a partir da ótica dos próprios sujeitos envolvidos.

\section{Saberes docentes: identificando enfoques e tipologias}

Ao discutir a questão dos saberes docentes e a formação de professores, não nos arriscaríamos a dizer que o estudo desta temática é algo inédito, já que, de certa forma, vinha sendo estudada através da 
discussão de temas como a prática docente, o processo ensino-aprendizagem, a relação teoria-prática no cotidiano escolar etc., num contexto diferenciado, onde a escola era tida como "local" privilegiado para a transmissão do saber pelo professor, que detinha todo o conhecimento a ser repassado ao aluno.

No entanto, considerando que tanto a escola como os professores mudaram, a questão dos saberes docentes agora se apresenta com uma outra "roupagem", em decorrência da influência da literatura internacional ${ }^{6}$ e de pesquisas brasileiras, ${ }^{7}$ que passam a considerar o professor como um profissional que adquire e desenvolve conhecimentos a partir da prática e no confronto com as condições da profissão.

Considerando os estudos estrangeiros que têm servido de referência para as pesquisas brasileiras, colocando em evidência diferentes tipologias e apresentando a complexidade e o caráter polissêmico que envolve a noção de saber docente e, nesse sentido, dos saberes que são mobilizados pelo professor em sua prática pedagógica, destacamos aqueles desenvolvidos pelos pesquisadores do Crifpe. ${ }^{8}$ Segundo Tardif et al. (1991), ${ }^{9}$

quanto mais um saber é desenvolvido, formalizado, sistematizado, como acontece com as ciências e os saberes contemporâneos, mais se revela longo e complexo o processo de aprendizagem que exige, por sua vez, uma formalização e uma sistematização adequada. (p. 219)

Neste artigo, os autores procuraram apresentar um esboço da problemática do saber docente e suas interferências na prática pedagógica, identificando as características e os diferentes tipos de saberes, a relação do professor com os saberes e a valorização dos saberes da experiência nos fundamentos da prática e da competência profissional. De um modo geral, o texto conclui reconhecendo a pluralidade ${ }^{10}$ e a heterogeneidade do saber docente, destacando a importância dos saberes da experiência que

surgem como núcleo vital do saber docente, a partir do qual o(a)s professor(a)s tentam transformar suas relações de exterioridade com os saberes em relações de interioridade com sua própria prática. Nesse sentido os saberes da experiência não são saberes como os demais, eles são, ao contrário, formados de todos os demais, porém retraduzidos, "polidos" e submetidos às certezas construídas na prática e no vivido. (p. 234) 
Em um outro artigo, Tardif (1999) analisa a questão dos saberes profissionais e a sua relação na problemática da profissionalização do ensino e da formação de professores. Considera que a diferença entre as profissões está na natureza do conhecimento profissional que, por sua vez, apresenta as seguintes características: a) é especializado e formalizado; b) é adquirido na maioria das vezes na universidade, que prevê um título; c) é pragmático, voltado para a solução de problemas; d) é destinado a um grupo que de forma competente poderá fazer uso deles; e) é avaliado e autogerido pelo grupo de pares; f) requer improvisação e adaptação a situações novas num processo de reflexão; g) exige uma formação contínua para acompanhar sua evolução; h) sua utilização é de responsabilidade do próprio profissional. A implantação e o desenvolvimento destas características no ensino e na formação de professores têm sido um dos objetivos do movimento da profissionalização docente que, nos últimos anos, tem buscado construir um repertório de conhecimentos e definir competências para a formação e a prática do magistério. ${ }^{11}$

Nesta perspectiva, considerando a existência de um repertório de conhecimentos de ensino que envolve os saberes profissionais do próprio professor, uma outra contribuição que chega ao Brasil é o estudo de Gauthier et al. (1998), que faz um levantamento das pesquisas norteamericanas sobre o que ficou conhecido como knowledge base, base de conhecimento. Seu estudo tem como ponto de apoio as premissas de que, assim como a atividade docente não tem conseguido revelar os seus saberes, as ciências da educação acabam por produzir outros saberes que não condizem com a prática. Gauthier e seus colaboradores identificam, então, a existência de três categorias relacionadas às profissões: ofícios sem saberes; saberes sem ofício e ofícios feitos de saberes.

A primeira categoria, ofícios sem saberes, abrangeria uma falta de sistematização de um saber próprio do docente envolvendo bom senso, intuição, experiência etc. Já os saberes sem ofício caracterizam-se pela formalização do ensino, reduzindo a sua complexidade e a reflexão que é presente na prática docente. Acabam-se tornando saberes que não condizem com a realidade. Esta categoria, de certa forma, não contribui para o fortalecimento da profissionalização docente. A terceira categoria apresenta um ofício feito de saberes, que abrangeria vários saberes que são mobilizados pelo professor e sua prática envolvendo o saber: a) Disciplinar, referente ao conhecimento do conteúdo a ser ensinado; b) Curricular, relativo à transformação da disciplina em programa de ensino; c) das Ciências da Educação, relacionado ao saber profissional específico que não está diretamente relacionado com a ação pedagógica; d) da Tradição $P e$ - 
dagógica, relativo ao saber de dar aulas que será adaptado e modificado pelo saber experencial e, principalmente, validado ou não pelo saber da ação pedagógica; e) da Experiência, referente aos julgamentos privados responsáveis pela elaboração, ao longo do tempo, de uma jurisprudência de truques etc.; f) da Ação Pedagógica, que se refere ao saber experencial tornado público e testado. Segundo o autor, os saberes docentes são aqueles adquiridos para o ou no trabalho e mobilizados tendo em vista uma tarefa ligada ao ensino e ao universo de trabalho do professor, exigindo da atividade docente uma reflexão prática.

Percebe-se aí uma nova fundamentação da pedagogia e do trabaIho do professor; este passa a ser visto como um "profissional, ou seja, como aquele que, munido de saberes e confrontando a uma situação complexa que resiste à simples aplicação dos saberes para resolver a situação, deve deliberar, julgar e decidir com relação à ação a ser adotada, ao gesto a ser feito ou à palavra a ser pronunciada antes, durante e após o ato pedagógico" (p. 331). A concepção de saber, para o autor, não impõe ao professor um modelo preconcebido de racionalidade. Dessa forma, o saber do professor pode ser racional sem ser um saber científico, pode ser um saber prático que está ligado à ação que o professor produz, um saber que não é o da ciência, mas que não deixa de ser legítimo. Assim, o saber é considerado como resultado de uma produção social, sujeito a revisões e reavaliações, fruto de uma interação entre sujeitos, fruto de uma interação lingüística inserida num contexto e que terá valor na medida em que permite manter aberto o processo de questionamento. Ao se pensar um modelo de professor, deve-se levar em conta o contexto no qual se constroem e se aplicam os saberes docentes, isto é, as condições históricas e sociais nas quais se exerce a profissão; condições que servem de base para a prática docente. Este professor possui, em virtude da sua experiência de vida pessoal, saberes próprios que são influenciados por questões culturais e pessoais.

Referências estrangeiras como estas têm nos orientado na busca de novos caminhos de pesquisa sobre os saberes e a formação docente, com características próprias de nossa realidade, conforme a análise de alguns estudos que apresentaremos a seguir.

A fim de repensar a formação inicial e contínua a partir da análise das práticas pedagógicas, Pimenta (1999) desenvolve uma pesquisa a partir de sua prática com alunos de licenciatura e destaca a importância da mobilização dos saberes da experiência para a construção da identidade profissional do professor. Neste sentido, são identificados três tipos de saberes da docência: a) da experiência, que seria aquele aprendido 
pelo professor desde quando aluno, com os professores significativos etc., assim como o que é produzido na prática num processo de reflexão e troca com os colegas; b) do conhecimento, que abrange a revisão da função da escola na transmissão dos conhecimentos e as suas especialidades num contexto contemporâneo e c) dos saberes pedagógicos, aquele que abrange a questão do conhecimento juntamente com o saber da experiência e dos conteúdos específicos e que será construído a partir das necessidades pedagógicas reais. A autora enfatiza ainda a importância de que a fragmentação entre os diferentes saberes seja superada, considerando a prática social como objetivo central, possibilitando, assim, uma re-significação dos saberes na formação dos professores.

O estudo de Fiorentini (1998), partindo do eixo da relação teoria/ prática, procurou identificar e caracterizar os saberes docentes e como estes poderiam ser apropriados/produzidos pelos professores através de uma prática pedagógica reflexiva e investigativa. Segundo ele, a relação que cada grupo (acadêmicos e professores) mantém com os saberes é que fará a diferença, "relação essa que, na maioria das vezes, é decorrente de uma cultura profissional marcada pela racionalidade técnica que supervaloriza o conhecimento teórico ou pelo pragmatismo praticista ou atividade que exclui a formação e a reflexão teórica e filosófica". (p. 311). Concluiu que a articulação da teoria com a prática poderá contribuir na formação do professor/pesquisador de forma contínua e coletiva, utilizando a prática pedagógica como instância de problematização, significação e exploração dos conteúdos da formação teórica. Na realidade brasileira, as pesquisas educacionais da prática escolar parecem priorizar dois tipos de interesse que constituem o saber, segundo Haberman (apud Fiorentini, 1998): o interesse técnico instrumental, em que se utilizam explicações científicas objetivas, baseado no modelo da racionalidade técnica; e o interesse prático, que efetiva a interpretação dos significados produzidos pelos praticantes do mundo-vida como subsídio para a emissão de um juízo prático. Haveria ainda um terceiro que seria o interesse emancipatório, aquele que "exige que se ultrapassem quaisquer interpretações estreitas e acríticas para com os significados subjetivos, a fim de alcançar um conhecimento emancipador que permite avaliar as condições/determinações sociais, culturais e políticas em que se produzem a comunicação e a ação social" (p. 315).

A partir da idéia de que a profissão vai sendo construída à medida que o professor articula o conhecimento teórico-acadêmico, a cultura escolar e a reflexão sobre a prática docente, Guarnieri (1997) desenvolve um estudo acerca da atuação de professores iniciantes. Revisando as novas 
perspectivas de pesquisa que analisam a questão da competência para ensinar, enfatiza que "esses novos paradigmas investigativos buscam a partir do pensamento e desenvolvimento profissional dos professores "uma epistemologia da prática" que explique como se configura o processo de aprender a ensinar, de tornar-se professor" (p. 2) Dessa forma, numa tentativa de superar o modelo da racionalidade técnica, as pesquisas e os cursos de formação de professores precisam redirecionar as relações entre teoria e prática, centrando as análises na prática docente e

procurando identificar quais conhecimentos são desenvolvidos pelo professor ao atuar, no âmbito da cultura escolar e das condições mais adversas do seu trabalho. Também busca especificar e estudar as necessárias articulações desses conhecimentos do professor tanto com a prática, quanto com os conhecimentos teóricos acadêmicos da formação básica. Tais articulações possibilitam o desenvolvimento da capacidade reflexiva, que favorece o compromisso com o ensino de qualidade e a competência para atuar. (p. 6)

Considerando tais idéias no desenvolvimento da pesquisa, destaca a possibilidade de que na prática pedagógica do professor iniciante apareçam alguns aspectos como: a rejeição dos conhecimentos teóricos acadêmicos recebidos na formação por dificuldade em aplicá-los; a tentativa de transposição direta de uma concepção teórica; a percepção dos aspectos positivos da prática docente e da cultura escolar e como estas se apresentam no contexto do trabalho, podendo ser consideradas como parâmetros para sua própria prática. Suas análises enfatizaram o quanto o professor aprende a partir da prática, embora reconheça que os cursos de formação de professores, tanto inicial como continuada, ainda não favorecem a articulação entre a formação teórica acadêmica e os conhecimentos oriundos do universo escolar.

A pesquisa desenvolvida por Damasceno e Silva (1996) envolve a questão do saber docente na sua prática pedagógica e na relação do saber advindo da prática social. ${ }^{12} \mathrm{O}$ estudo foi desenvolvido em escolas do ensino fundamental e a partir dos dados levantados pôde-se perceber o quanto o trabalho docente ainda tem sido embasado por uma racionalidade instrumental. No entanto, os professores percebem a importância de se desenvolver uma prática pedagógica mais consistente que esteja mais diretamente ligada com a vida das crianças. Dessa forma, 
pensar na formação do professor envolve, assim, capacitá-lo, dentre outras coisas, para lidar com o conflito resultante do confronto entre os saberes diversificados dos diferentes grupos sociais que freqüentam a escola, e aquele saber sistematizado presente em um determinado momento histórico-social e que a escola se propõe a transmitir. (p. 20)

Um outro estudo que procura analisar a construção do saber docente junto a professores de Educação Física é desenvolvido por Borges (1995). Focaliza especificamente a trajetória profissional de dois professores de Educação Física a partir da análise de sua formação e prática pedagógica. Pôde identificar que tanto as experiências vivenciadas no processo de escolarização, quanto as experiências esportivas, acadêmicas e profissionais contribuem na gênese dos saberes que eles mobilizam no cotidiano da prática escolar. Dessa forma, analisando a divisão existente entre quem produz e quem transmite os conhecimentos, propõe que "talvez se possa pensar que a valorização dos saberes da experiência, dos saberes docentes de um modo geral, seja uma alternativa no sentido de buscar uma maior aproximação da formação acadêmica com a realidade escolar, estreitando os vínculos na relação entre teoria e prática." (p. 14).

Uma outra pesquisa é o trabalho desenvolvido por Caldeira (1995), que se interessava em investigar os saberes implícitos construídos e apropriados pelo professor em sua prática durante sua trajetória profissional e pessoal. Partindo dessa suposição (de que o docente se apropria e produz saberes na atividade escolar), a autora procurou descrever e analisar a prática docente de uma professora do ensino fundamental e a reconstrução do processo de constituição do seu saber. Ressalta a importância de considerar o estudo da prática docente como processo informal, dinâmico, complexo e carregado de valores. Recorrendo ao estudo de Tardif et al. (1991), considera os diversos tipos de saberes (das disciplinas, curriculares, profissionais e da experiência) como integrantes da prática docente, sendo que a diferença estaria na relação do professor com cada um deles.

Com os saberes das disciplinas curriculares e de formação profissional mantém uma "relação de exterioridade", ou alienação, porque já os recebe determinados em seu conteúdo e forma (...) Portanto esses conhecimentos não Ihes pertencem, nem são definidos ou selecionados por eles. (...) Não obstante, com os saberes da experiência o professorado mantém uma "relação de interioridade". E por meio dos saberes da experiência, os docentes se apropriam dos saberes das disciplinas, dos saberes curriculares e profissionais. (p. 8) 
Embora reconhecendo as condições singulares em que foi desenvolvida a pesquisa, a autora destaca o "valor" do saber produzido na prática cotidiana do professor. Saber esse que resulta de um processo de reflexão realizado coletivamente a partir das "condições materiais e institucionais" da escola, considerando a dimensão histórica e social em que é construída a prática docente.

A partir dos estudos apresentados, percebemos que, embora existam diferentes tipologias e formas de abordar a questão dos saberes docentes, é importante considerar na investigação da questão não só o desenvolvimento profissional como também o desenvolvimento pessoal do professor, enfatizando que o saber é constituído a partir do contexto histórico e social vivenciado e transformado em saber da experiência.

\section{Concluindo e encaminhamentos futuros...}

Percebemos com este estudo inicial que a investigação dessa temática tem possibilitado identificar um percurso de pesquisa relacionado aos saberes e à formação de professores, desenvolvido com características próprias, mas em compasso com uma tendência internacional no âmbito das pesquisas sobre o ensino e sobre os docentes.

De certa forma, o repensar a concepção da formação dos professores, que até a pouco tempo objetivava a capacitação destes, através da transmissão do conhecimento, a fim de que "aprendessem" a atuar eficazmente na sala de aula, vem sendo substituído pela abordagem de analisar a prática que este professor vem desenvolvendo, enfatizando a temática do saber docente e a busca de uma base de conhecimento para os professores, considerando os saberes da experiência.

Tardif (1999), analisando o modelo aplicacionista ${ }^{13}$ da universidade, apresenta algumas possibilidades promissoras nesse campo de trabalho para os pesquisadores universitários que atuam na área de formação de professores: seja na elaboração de um repertório de conhecimentos para o ensino, baseado no estudo dos saberes profissionais dos professores ${ }^{14}$ tais como estes mobilizam e utilizam em diversos contextos do trabalho cotidiano, seja na introdução de dispositivos de formação, ação e pesquisa que constituam os saberes e as trajetórias da carreira no meio universitário, mas que sejam úteis para os professores em sua prática, na busca de uma ruptura da lógica disciplinar da universidade que, fragmentando os saberes, impede a socialização profissional e, por fim, considerada pelo autor como a mais urgente, seria a reflexão da sua própria 
prática de ensino pelo professor universitário de forma a minimizar o abismo existente entre as "teorias professadas" e as "teorias praticadas".

Considerando que a tarefa do professor tem como característica ser um trabalho interativo, Gauthier (1998) enfatiza a dificuldade de trabalhar com os saberes formalizados. Sugere, assim, que pesquisas sobre o saber da Ação Pedagógica poderiam contribuir para o aperfeiçoamento da prática docente e formação de professores, considerando, além dos conhecimentos científicos (provenientes da pesquisa acadêmica), o saber nascido da prática, opondo-se às abordagens dos estudos que procuravam separar formação e prática cotidiana, que nos anos de 1980 estavam no centro das análises, enfatizando a questão técnica e política do trabaIho pedagógico.

Com este panorama traçado, analisando alguns estudos sobre a questão dos saberes docentes e a formação dos professores, tentamos identificar como está este campo de pesquisa na realidade brasileira. Salientamos que ainda pode ser considerada uma área um tanto nova, carente de estudos empíricos que possam responder algumas questões tais como: como são transformados os saberes teóricos em saberes práticos? Existe um "conhecimento de base" a ser considerado na formação do professor? Como é constituído o saber da experiência? Teria ele uma maior "relevância" sobre os demais saberes? A investigação de questões como estas, entre outras referentes ao saber docente, com certeza muito contribuirá para o desenvolvimento desse campo de pesquisa na realidade brasileira, assim como para as orientações de políticas voltadas para a formação e profissionalização do professor.

Recebido para publicação em 16 de janeiro de 2001.

\section{Notas}

1. Percebe-se ainda que esta temática vem se tornando cada vez mais expressiva, indo além do campo da formação de professores, sendo explorada também na área da Didática e do Currículo (o que pode ser percebido na análise da produção acadêmica apresentada nos Anais da Anped).

2. Abordagem esta que estava no centro das análises nos anos de 1980 , quando se enfatizava a questão técnica e política do trabalho pedagógico. A competência profissional do professor envolveria tanto o domínio dos conteúdos como o seu entendimento a respeito das relações entre os vários aspectos da escola, incluindo-se ainda o peso da formação técnica sobre o modo como percebe a organização da escola e os resultados da sua ação. Em um texto emblemático deste período, Mello (1983) aponta como a organização social 
do trabalho no interior da escola acabara por fazer com que o professor perdesse seus instrumentos de trabalho: do conteúdo (saber) ao método (saberfazer), restando uma técnica sem competência. Na busca por mapear as causas da precariedade da prática docente estava a dificuldade do professor em se perceber como parte do problema do ponto de vista das deficiências da sua formação. O fracasso da escola, então, passa a ser justificado por essa "incompetência" do professor, que apresentava problemas de formação como falta de articulação entre teoria e prática, entre formação geral e formação pedagógica, entre conteúdos e métodos de ensino.

3. Através de autores como Nóvoa, Ferrarotti, Dominicé, Huberman, Goodson, entre outros.

4. Tais como "profissionalização e/ou proletarização do magistério, cultura escolar, socialização profissional, feminização do magistério, etapas da carreira docente e formação continuada, bem como pensamento, tarefas, tomadas de decisão, saberes, crenças e valores dos professores." (p.1).

5. Resultante "da transformação na práxis dos diversos saberes instituídos (curriculares, disciplinares e de formação profissional), bem como de saberes da prática social e da cultura." (p.1).

6. A partir de autores como Tardif, Gauthier, Shulman, entre outros.

7. A partir de autores como Fiorentini, Therrien, Pimenta, Silva, Penin, entre outros.

8. Centre de Reserche Interuniversitaire sur la Formation et la Profession Enseignante.

9. Nos arriscaríamos a dizer que este artigo foi um dos impulsionadores dos estudos sobre os saberes docentes em nossa realidade.

10. Referindo-se ao "saber formado de diversos saberes provenientes das instituições de formação profissional, do currículo e da prática cotidiana” (p. 233).

11. Segundo Tardif (1999), "se esses esforços e reformas forem bem sucedidos, o ensino deixará, então, de ser um ofício para tornar-se uma verdadeira profissão, semelhante à profissão de médico ou às profissões de engenheiro e de advogado" (p.10).

12. “(...) é no contexto da racionalidade interativa que emerge [sic] os saberes da prática social enquanto um dos elementos constitutivos dessa prática, fruto da ação comunicativa dos atores sociais" (Damasceno e Silva, 1996, p. 2).

13. A universidade organizada neste modelo estabelece uma separação entre a pesquisa (produção do conhecimento), formação (formação relativa a esses conhecimentos) e prática (mobilização dos conhecimentos).

14. Mesmo que não possamos considerar que "para os professores, por exemplo nem sempre é fácil teorizar a sua prática e formalizar seus saberes, que eles vêem como sendo pessoais, tácitos e íntimos" (Tardif, 1999, p. 32). 


\section{TEACHER'S KNOWLEDGE AND TEACHER'S EDUCATION: \\ A PANORAMA OF BRAZIUIAN RESEARCH}

ABSTRACT: The researches about teacher's education and profession point to a comprehension's revision of pedagogical practice of the teacher who is consider as a professional knowledge mobilizer. It consider so, that this, in your trajectory, build and rebuild your knowledge as according to the necessity of your utilization, your experiences, your professional and formative routes, etc. The objective of this text is present analysis of how and when the question of teachers knowledge appears on researches about teacher's education in the brazilian educational literature, identifying the different references and theoretical-methodological approaches that justify them, the focus and typology utilized and created by brazilian researchers. It believes that the investigations of this thematic will allow identify a way of research developed with own characteristics, but in time with a international tendency in the scope of researches about teaching and about teachers.

Key words: teacher's knowledge, knowledge, teacher's education, educational research, teaching.

\section{Referências bibliográficas}

ANDRÉ, M.E.D. Perspectivas atuais da pesquisa sobre docência. In: CATANI, D.B. et al. Docência, memória e gênero: Estudos sobre formação. São Paulo: Escrituras Editora, 1997.

BORGES, C.M.F. Formação e prática pedagógica do professor de educação física: A construção do saber docente. In: Anais da $19^{a}$ Anped, 1996 (disq.).

CALDEIRA, M.S. A apropriação e a construção do saber docente e a prática cotidiana. Cadernos de Pesquisa no 95, São Paulo, nov. 1995, p. 5-12.

DAMASCENO, M.N. \& SILVA, I.M. Saber da prática social e saber escolar: Refletindo essa relação. In: Anais da $19^{a}$ Anped, 1996 (disq.).

DURAN, M.C.G. \& NASCIMENTO, D.R.C. Formação do educador: Uma discussão dos saberes que integram o processo. In: Anais da $22^{3}$ Anped, 1999 (CD room).

FIORENTINI, D. \& SOUZA e MELO, G.F. Saberes docentes: Um desafio para acadêmicos e práticos In: GERALDI, C. (org). Cartografias do 
trabalho docente: Professor(a)-pesquisador(a). Campinas: Mercado das Letras, ALB, 1998.

GUARNIERI, M.R. O início na carreira docente: Pistas para o estudo do trabalho do professor. In: Anais da Anped, 1997 (disq.).

GOODSON, I. Dar voz ao professor: As histórias de vida dos professores e seu desenvolvimento profissional In: NÓVOA, A. (Org.). Vidas de professores. Porto: Porto Editora, 1995.

MELLO, G.N. de. Magistério de $1^{\circ}$ grau. Da competência técnica ao compromisso político. São Paulo: Cortez, 1983

NÓVOA, A. (Org.). Vidas de Professores. Porto: Porto Editora, 1992.

NÓVOA, A. Os professores e as histórias da sua vida. In: (Org.). Vidas de professores. Porto: Porto Editora, 1995.

PIMENTA, S.G. Formação de professores: Identidade e saberes da docência. In: PIMENTA, S.G. (Org.) Saberes pedagógicos e atividade docente. São Paulo: Cortez, 1999.

PENIN, S.T. A professora e a construção do conhecimento sobre o ensino. Cadernos de Pesquisa, no 92, São Paulo, fev. 1995, p. 5-15.

SILVA, M.H.G.F. Saber docente: Contingências culturais, experenciais, psico-sociais e formação. In: Anais da $20^{a}$ Anped, 1997 (disq.).

Sabedoria docente: Repensando a prática pedagógica. Cadernos de Pesquisa no 89, maio 1994, p. 39-47.

TARDIF, M.; LESSARD \& LAHAYE. Os professores face ao saber: Esboço de uma problemática do saber docente. Teoria \& Educação no 4, Porto Alegre: Pannônica, 1991.

TARDIF, M. Saberes profissionais dos professores e conhecimentos universitários. Rio de Janeiro: PUC, 1999.

THERRIEN, J. Uma abordagem para o estudo do saber da experiência das práticas educativas. In: Anais da $18^{a}$ Anped, 1995 (disq.). 